lidades. Páez, Santander, Bermúdez, todas las figuras secundarias que no hubieran podido existir sin Bolívar, se creyeron iguales y hasta superiores a él. La emulación febril, signo fatídico bajo el cual nacieron nuestras repúblicas a la vida independiente, no respetó nunca los valores. Un fermento irrespetuoso y cerril se opuso a todas las grandezas posibles. Por un corazón dispuesto al sacrificio como el de Sucre, había cien avideces de preeminencia. Y este individualismo egoísta y anárquico, fuente de inmovilidad y anemia para los grupos sociales, ha sido el punto de partida de las desgracias que se han abatido sobre nuestras tierras, desde el régimen tiránico, hasta el imperialismo devorador.

Dentro de la brevedad de una vida, Bolívar puso sus formidables capacidades al servicio de una alta aspiración que, siendo superior al tiempo que nos concede la naturaleza, era también superior a las vanidades. Se jugó en la lucha por un porvenir que no debía ver y en defensa de una patria de la cual no sería ya ciudadano. Lo que nos ha perdido, en cambio, en América, ha sido el afán de conquistar cada uno para sí, como si cada hombre fuese una potencia autónoma dentro del Continente, como si cada vida marcase el límite extremo de la duración de los pueblos.

Una nación es un ideal, alrededor del cual se suceden generaciones, que son a la vez fruto y simiente. Si el ideal rueda, no queda más que una dispersión de apetitos. La patria está más allá de nuestros intereses; y aunque las catástrofes se produzcan después de nuestra muerte, debemos considerarnos alcanzados por ellas.-MA N UEL U GA R TE.

Exclusivo para Atenea en Chile.

\title{
OTROS ASPECTOS DE GOETHE
}

\section{II}

$\mathbb{C}$

UANTOS renunciamientos! Y ahí, cerca de él, Beethoven, que se hubiera sentido feliz de trabajar con él y para él, de poner música al Fausto, de escribir, bajo su dictado, un oratorio haendeleano.

El último golpe es el recibido en Febrero de 1816, cuando al querer presentar en su teatro de Weimar un Festspiel, con

(1) Véase el número anterior de Atenea. 
música en honor de la victoria alemana: Des Epimenides Erwachen (El despertar de Epiménides) los músicos, sus músicos, se burlan de él y de su obra. Ni siquiera tienen el pudor de disimularlo. Goethe se siente herido. Declara que desde ese día no tolerará que se presente en Weimar ninguna obra musical nueva compuesta sobre sus poemas. Y tal es el fin de cuarenta años de laboriosos esfuerzos, para casar en el teatro su poesía con la música. Derrota completa y humillante.

Pero si se le rehusaba el teatro, si él mismo, fatigado, desilusionado no quería asistir más que de cuando en cuando a una representación, no ha renunciado por eso a su sueño. Menos que nunca; porque se concentra en él, en el teatro de su pensamiento. Se crea su teatro en libertad, su bpera invisible, su gran drama lírico. Y este es el Segundo Fausto.

No hay dudas acerca de esto. Nosotros no planteamos una hipótesis. Lo ha dicho él mismo. Es la corriente que se expande por todas las rutas de la poesía y de la música acumuladas en su interior durante toda su vida. Quiere que la representación recurra a todos los recursos de la música instrumental, del canto, de los coros, de la mise en scène de la ópera. Se lo declara francamente a Eckermann:

La primera parte de Fausto necesita de los primeros artistas de la tragedia (1). En seguida en la parte de la ópera (im Teiler der Oper), los roles deben estar a cargo de los primeros cantores y cantatrices. La parte de Elena no podrá ser confiada a una, sino a dos grandes artistas; porque es muy raro encontrar una cantante que sea al mismo tiempo una artista trágica de primera línea.

Pero ¿dónde hallar el compositor que uniese, conforme al deseo expresado por Goethe, la naturaleza alemana al estilo italiano, el segundo Mozart? Goethe parece no encontrarlo. Se diría que no tiene ninguna impaciencia para asistir a la realización material de su obra. A las impaciencias de Eckermann responde con calma:

Esperemos lo que los dioses nos han de traer (2). No es necesario impacientarse en estos casos. Llegará el tiempo ęn que el sentido de esta obra se manifestará a los hombres, en que los directores de teatros, los poetas y los compositores encontrarán sus bondades.

No se interesa en el resultado. Ya no se inquieta por ver

(1) 29 de Enero de 1827.-A Eckermann le parece extraño que la pieza comience como tragedia y termine como ópera. Goethe responde: Si, asi es. Tal ha sido mi voluntad.

(2) Tenía entonces ochenta años. 1829. 
en la escena la obra de su espíritu. La ha visto en su propio espíritu (1). De este modo concluye el esfuerzo de toda una vida para crear un teatro nuevo. Renunciamiento y repliegue dentro de sí mismo.

¡Cuánto se ha valorizado el Segundo Fausto, por ser la suma de sueño de poesía y de música, que Goethe había amalgamado en su teatro interior! iY cómo se ilumina esta obra inmensa, que queda al margen de toda crítica y rompe todas las formas admitidas! Es este un mundo, en los primeros días de la creación, cuando el Espíritu separa las aguas, que espera siempre que se haga la luz sobre el Segundo Goethe, el músico (2).

De ninguna manera quisiera yo que por estas líneas se juzgase que considero el Segundo Fausto como un gigantesco libretto. Un libretto no es más que la mitad de un poema. Una obra de Goethe, aun aquellas que han sido hechas para ponerlas en música, es un poema y medio. Contiene la música en sí misma. Así los versos que he citado al principio de este ensayo: Nur nicht lesen! immer singen!, son un canto. Más aun: una orquesta. Anuncia, por momentos, en el Fausto $I$ y $I I$, todos los esplendores instrumentales de las épocas románticas, wagneriana y las siguientes.

Felipe Spitta lo ha visto bien: Goethe, cuyos oídos envejecidos estaban cerrados a la nueva música: Beethoven, Schubert y Weber, era entonces el creador del mundo poético que ellos ilustraban con sus colores y sus frescos. $\mathrm{Y}$, posteriormente, creaba una música que los sobrepasaba. Ningún genio musical ha podido, y no podrá jamás producir un lied como algunos lieder de Goethe, que comprendían en dos líneas la inmensidad:

-Ueber allen Gipfeln.

ist Ruh...

-Was...

durch das Labyrinth der Brust

wandelt in der Nacht...

Spitta ha dicho de ellos: son demasiado profundos para poder ser puestos en música. La música instrumental podría arriesgarse a evocar sólo la ilusión. Pero esto no sería más que la

(1) Aquí se impone ante nosotros la imagen del viejo visionario, tal como ella apareció a los ojos del joven hijo de Bettine, diez días antes de su muerte: - Parece ahora pertenecer a otro mundo, más que a este; y los cuadros de su fantasía parecen hacerle olvidar todos los hechos, todo lo que pasa aquí abajo.»

(2) No es que los músicos no lo hayan intentado. Pero ninguno-ni siquiera Schumann que ha tentado la última escena en l'Audeld-ha tenido el doble genio del Norte y el Mediodía, que Goethe exigía y tenía. 
atmósfera, el orbe mágico, pero el orbe vacío. Siempre hará falta a esas grandes ondas de luz que se alzan en el océano sonoro la palabra precisa que las encadene y concentre bajo su sello el Espíritu.

Goethe ha creado una Sprechmusik (música de la palabra). Y lo supo hacer porque quiso, en la época en que reinaba sobre un pequeño pueblo de declamadores y comediantes, imponer la más estricta escuela, la de la palabra musical. Sobre todo en los comienzos del siglo, entre 1800 y 1807 , se empeñaba vigorosamente y somete a la tribu de Weimar a su férula de director de orquesta. No hay en esta frase nada de metafórico, puesto que llega a servirse de una batuta para dirigir los ensayos teatrales. Durante esa época, por reacción contra el naturalismo, quería, como Schiller, que la tragedia tomara a la ópera por modelo... Pretendía que cada compañía de actores fuera una orquesta, donde cada instrumentista se subordinara al conjunto y ejecutara su parte puntualmente.

A nadie se le ocurre la idea-dice Wilhelm Meister a los actores (1)-de hacerse notar (en la sinfonía), acompañando con gran ruido el solo de otro; cada cual procurará tener trascendencia en el sentimiento y el espíritu del compositor $y$ desempeñar bien la parte que se le ha confiado, tenga o no importancia. ¿No deberíamos trabajar con la misma precisión, con la misma inteligencia, nosotros que cultivamos un arte más graduado que toda especie de música, puesto que estamos llamados a representar, con buen gusto y de buen grado, lo que hay de más común y de más raro en la vida humana?

Como en ese momento Wilhelm se encuentra, por gracia principesca, dueño de Philine y de la compañía (se jacta de ello, pero no por mucho tiempo, Philine se acuesta con el príncipe y la compañía ríe en las barbas de Wilhalm), quiere poner en práctica su deseo. Dirige a sus comediantes como un Kapellmeister sus cantores y su orquesta (2). Impone severamente

(1) Lehrjahre, IV, 2.

(2) Podría agregar: sus coros. En efecto, una de sus principales preocupaciones era el coro en la tragedia. Había experimentado esta poderosa atracción por la tragedia griega y por Haendel y Gluck, que le parecían (justamente) los herederos de ese gran arte coral antiguo. Ensaya las diversas posibilidades en sus poemas musicales y especialmente en el Segundo Fausto. El problema reside, sobre todo, en la realización práctica, en el teatro; y La Fiancée de Messine ofrece un campo de experiencias para ser realizadas en la escena en Weimar. Schiller se había contentado con hacer declamar buenamente los coros al unísono. El efecto era mediano, frío y confuso. Goethe organiza, en el tercer acto, los dos coros antagonistas en soli, dúos, tríos y coros alternados, crescendi y decrescendi, teniendo en cuenta los diversos registros de voz. (Algunas de esas disposiciones ingeniosas se hallarán anotadas en las Memorias de Genast.) 
la estricta exactitud de sus tempi, de sus movimientos, de sus gradaciones: forle, piano, crescendo, diminuendo... En 1803 escribe sus Regeln für Schauspicler, con el objeto de concretar sus doctrinas. Llama a la declamación un arte de música en prosa (1) (eine prosaische Tonkunst). Anota, al margen de La Fiancée de Messine, como en una partitura de ópera, las gradaciones musicales de la declamación:

-Aquí, ahogado, a media voz...

- Aquí, más claro, más resonante...

-Aquí, sordamente...

-Aquí, profunda y fríamente...

-Aquí, otro tiempo, más rápido...

Estas indicaciones no le bastan: necesita, como los músicos de la época (Beethoven), un metrónomo de Maelzel. Dibuja para su escuela de conversacion musical toda una tabla de medidas, donde inscribe la duración de cada palabra, de cada silencio. Llega hasta dibujar al milímetro cada signo de puntuación:

Esta ficción germánica a la regla y la disciplina algunas veces lo hace correr el peligro de congelar su impulso creador. Bajo el poeta asoma el sargento... Parece que tal método sólo puede conducir a la mecanización de un regimiento que ejecuta, a las voces de mando, el ejercicio con armas. Pero Antón Genast dice que el profesor instructor no impone este automatismo más que a los principiantes y poco a poco les da rienda, cuando ya dominan el instrumento (2).

No sólo la compañía está sometida a las leyes de una orquesta. El maestro-poeta obedece en su creación al espíritu de la música. En plena madurez (1796-1806) llega a anotar, antes de escribir la obra, con palabras sin sentido ni ilación, las sonoridades y la medida de cada trozo. A los versificadores que lo llaman

(1) Musik war sie zu nennen, dice Genast de la declamación que imponía: Se podía llamar una mísica.

(2) A todos los que se interesen por el teatro les recomiendo los Recuer dos de Genast: Aus Weimars klassischer und nachklassischer Zeit Erinnerungen eines alten Schauspielers. 
al respeto del código tradicional de metros y rimas, responde: ¡La música primero!

Pero esta música no tiene nada de la de los músicos. Pretende crear otra, aparte, personal (1); y la juzga superior a la sin palabras. Después de haberse penetrado de esto, el poetarey recobra el cetro al que no había renunciado ni por un instante:

El mérito de la hermosa palabra humana-escribe a Knebel-supera por mucho a la del canto. No se puede comparar: sus inflexiones y sus modulaciones son incontables (2), por la expresión del sentimiento. El mismo canto ha de volver a la simple palabra, cuando necesita alcanzar la altura de lo dramático y de la emoción. Esto lo han demostrado todos los grandes compositores.

Así la música no es como la conciben los grandes músicos, un acabamiento de la palabra. Es la palabra del poeta el acabamiento de la música.

$\mathrm{Y}$ en ambos casos cada cual está en lo cierto, cuando actúa el genio. Porque este abraza el mundo interior, el Yo total. $\mathrm{Y}$ si varían los elementos que usa para expresarlo, la suma de ellos permanece idéntica. Un Goethe es músico en poesía, como un Beethoven es pöeta en música. $Y$ aquellos que no son músicos y no son poetas, no son más que reyezuelos confinados en sus provincias. Goethe y Beethoven son emperadores del Alma-Universo.- R o M A I N R o L L A N D.

Exclusivo para Atenea en Chile.

(1) Ya he señalado la oposición que en esto había entre Goethe y Schiller, que tenía demasiada inclinación hacia el hablar en mísica, esto es, hacia el melodrama. Goethe reivindica la independencia musical de la palabra poética: en él es una música autónoma, que tiene existencia propia; lleva en sí misma su orquesta y sus cantos.

(2) En efecto, la declamación poética de Goethe es, hacia 1800, extremadamente matizada. El pastor Ewald Offenbach escribe en 1799:

Con pocos tonos enteros traducía todo lo que quería. Esta declamación tenía intervalos extremadamente pequeños. Entre ut y re hubieran podido contarse tal vez seis sones, que no se habrían podido anotar musicalmente. Esta declamación estaba caracterizada por el ataque (la entrada), la melodía, el paso a otra melodía y el regreso a la primera tonalidad. (Se creería estar leyendo un primer trozo de una sonata de la época.)

Pero con la edad pierde ese arte de matizar, o lo sacrifica voluntariame, a la alegría de la sonoridad. Le gusta demasiado hacer vibrar, al leer, su h mosa voz de bajo, y su inflexión es demasiado marcada. Se le ha reproch: varias veces. (Es preferible en la lectura de lo cómico. Es - ¿quién lo hubi creído? - un Falstaff incomparable..... Genast lo atestigua.) Entretan conserva siempre en la conversación una entonación dulce y mesurada. Peru tiene demasiada vida y fuerza (verdaderamente brutal) que gastar. Le da a su expresión y a su juego dramático una violencia tal, que cierta vez, en un ensayo del Rey Juan, hace caer con convulsiones a una pequeña actriz que le replica. 